УДК 548.5+661.8

\title{
БОРАТ АЛЮМИНИЯ И МЕТОДЫ ЕГО СИНТЕЗА ОБЗОР
}

\author{
() 2018 Е. Г. Яроцкая, П. П. Федоров \\ Институт общей физики им. А. М. Прохорова РАН, ул. Вавилова, 38, 119991 Москва, Россия \\ e-mail: yar461@yandex.ru
}

Поступила в редакцию 05.06.2018

\begin{abstract}
Аннотация. Представлены обзор различных технологий синтеза бората алюминия и диаграмма состояния системы $\mathrm{Al}_{2} \mathrm{O}_{3}-\mathrm{B}_{2} \mathrm{O}_{3}$.Приведены параметры синтеза и составы исходных компонентов шихты, а также габитус его кристаллов в зависимости от способов получения. Рассмотрены уникальные свойства бората алюминия в зависимости от целей получения конечного продукта. Приведены свойства полученного керамического бората алюминия, изучена его структура с применением широкого набора методов исследований.Анализ его свойств позволил определить возможные области применения материалов на основе пористой керамики в различных областях промышленности.
\end{abstract}

Ключевые слова: борат алюминия, нитевидные кристаллы, вискерсы, пористая керамика, композитные материалы

DOI: https://doi.org/10.17308/kcmf.2018.20/571

\section{ОБЩИЕ СВЕДЕНИЯ}

Под названием «борат алюминия» объединяются фазы, образующиеся в системе $\mathrm{Al}_{2} \mathrm{O}_{3}-\mathrm{B}_{2} \mathrm{O}_{3}$. Материалы на их основе активно исследуются в последние годы [1-30]. Минералогические аналоги этих фаз в природе не найдены, хотя известен редкий минерал еремеевит $\mathrm{Al}_{6}\left(\mathrm{BO}_{3}\right)_{5}(\mathrm{~F}, \mathrm{OH})_{3}$. По своей структуре бораты алюминия схожи с фазами, образующимися в системе $\mathrm{Al}_{2} \mathrm{O}_{3}-\mathrm{SiO}_{2}$ - силлиманитом и муллитом.

Характерной особенностью боратов алюминия является способность образовывать игольчатые/ нитевидные кристаллы (вискерсы, 1D-материалы) [31]. Форма частиц в сочетании с совокупностью свойств, таких как химическая устойчивость, малая плотность, хорошие механические свойства, низкий коэффициент термического расширения обусловили широкое применение боратов алюминия.

Борат алюминия обладает высокой устойчивостью к кислотам и щелочам, в том числе к воздействию горячих минеральных кислот, а также к расплавам боратных стекол. Этот материал может быть использован для изготовления технической керамики, как легковесный огнеупор, изоляционный материал в конструкциях ядерных реакторов и как упрочняющая добавка для композитов и сплавов. Материалы на его основе могут быть использованы в качестве антикоррозионного, теплоизоляционного или электроизоляционного материала.
Борсодержащие неорганические соединения являются эффективным поглотителем нейтронного излучения в объектах атомной промышленности. Возможно применение их в качестве наполнителя в термостойких резинах, цементах, керамиках, во многих композиционных материалах. На первый план в настоящее время выходит использование бората алюминия для упрочнения сплавов, в первую очередь алюминиевых.

Бораты алюминия обладают также каталитической активностью [17]. Предложено использовать фазы, образующиеся в системе $\mathrm{Al}_{2} \mathrm{O}_{3}-\mathrm{B}_{2} \mathrm{O}_{3}-\mathrm{SiO}_{2}$, в качестве матрицы для люминофоров при легировании $\mathrm{Eu}^{2+}[21]$. Из-за способности нитевидных кристаллов прокалывать оболочки клеток, борат алюминия используется в генной инженерии [16].

Система $\mathrm{Al}_{2} \mathrm{O}_{3}-\mathrm{B}_{2} \mathrm{O}_{3}$ изучалась Гилиссе и Фостером [1] методом закалки образцов, сплавленных в запаянной платиновой трубке. Ими обнаружено два соединения $9 \mathrm{Al}_{2} \mathrm{O}_{3} \cdot 2 \mathrm{~B}_{2} \mathrm{O}_{3}$ и $2 \mathrm{Al}_{2} \mathrm{O}_{3} \cdot \mathrm{B}_{2} \mathrm{O}_{3}$, см. рис. 1. Соединение $2 \mathrm{Al}_{2} \mathrm{O}_{3} \cdot \mathrm{B}_{2} \mathrm{O}_{3}$ плавится инконгруэнтно при $1035^{\circ} \mathrm{C}$. Предполагается, что соединение $9 \mathrm{Al}_{2} \mathrm{O}_{3} \cdot 2 \mathrm{~B}_{2} \mathrm{O}_{3}$ также плавится инконгруэнтно, но это заключение сделано методом экстраполяции. Авторы не исключают возможности существования твердых растворов в системе и несмешиваемости в жидкой фазе. Дальнейшие исследования дали температуру плавления $9 \mathrm{Al}_{2} \mathrm{O}_{3} \cdot 2 \mathrm{~B}_{2} \mathrm{O}_{3}$ значительно ниже, чем полагали Гилиссе и Фостер [1]. Согласно [28], плав- 
ление $9 \mathrm{Al}_{2} \mathrm{O}_{3} \cdot 2 \mathrm{~B}_{2} \mathrm{O}_{3}$ начинается при $1200-1400{ }^{\circ} \mathrm{C}$ в зависимости от состава, что является указанием на область гомогенности фазы.

Таким образом, область концентраций до 25 мол \% оксида бора характеризуется высокими температурами плавления. При большей концентрации $\mathrm{B}_{2} \mathrm{O}_{3}$ расплав появляется в системе уже при $470{ }^{\circ} \mathrm{C}$. Дальнейшие исследования, в первую очередь структурные, показали, что состав соединения $9 \mathrm{Al}_{2} \mathrm{O}_{3} \cdot 2 \mathrm{~B}_{2} \mathrm{O}_{3}$ намечен приблизительно. Предлагались другие стехиометрии, а именно $\mathrm{Al}_{5} \mathrm{BO}_{9}[11]$. Имеются структурные указания на узкую область гомогенности [28]. Согласно Мазза и др. [5] соединение $\mathrm{Al}_{5} \mathrm{BO}_{9}$ устойчиво до $900-1000{ }^{\circ} \mathrm{C}$, а при более высокой температуре переходит в фазу переменного состава на основе $9 \mathrm{Al}_{2} \mathrm{O}_{3} \cdot 2 \mathrm{~B}_{2} \mathrm{O}_{3}$, для которой предлагалась формула $\mathrm{Al}_{6-x} \mathrm{~B}_{x} \mathrm{O}_{9}$. Однако традиционно в литературе используется обозначение $9 \mathrm{Al}_{2} \mathrm{O}_{3} \cdot 2 \mathrm{~B}_{2} \mathrm{O}_{3}$ или $\mathrm{Al}_{18} \mathrm{~B}_{4} \mathrm{O}_{33}$.

При высоких давлениях синтезированы кристаллические фазы $\mathrm{AlBO}_{3}$ и $\mathrm{Al}_{3} \mathrm{BO}_{6}$ [13].

Строение боратов алюминия исследовалось с применением широкого набора методов $[1,5,17,19$, 28], включая рентгеновскую, электронную и нейтронную дифракцию, ядерно-магнитный резонанс ${ }^{27} \mathrm{Al}$ и ${ }^{11} \mathrm{~B}$, комбинационное рассеяние света. Структура $9 \mathrm{Al}_{2} \mathrm{O}_{3} \cdot 2 \mathrm{~B}_{2} \mathrm{O}_{3}$ описывается в ромбической сингонии, предлагались различные пространственные группы: $C m c 2_{1}, A 2_{1} a m$, Pbam и др., параметры решетки $\sim 5.68, \sim 15.0, \sim 7.69 \AA[11,28]$. Основной чертой структуры являются муллито-подобные цепи из октаэдров $\mathrm{AlO}_{6}$, связанных ребрами. Эти цепи связаны между собой полиэдрами $\mathrm{AlO}_{5}$, тетраэдрами $\mathrm{AlO}_{4}$ и треугольниками $\mathrm{BO}_{3}$. Некоторое количество бора в тетраэдрических позициях также присутствует.

По данным Гилиссе и Фостера [1] кристаллы бороалюмината описываются как ромбические кристаллы, образующие призмы (110), вытянутые по оси $c$, с совершенной спайностью по (001) и неясной по (111). Образуются двойники прорастания.

Для бората $9 \mathrm{Al}_{2} \mathrm{O}_{3} \cdot 2 \mathrm{~B}_{2} \mathrm{O}_{3}$ (моноклинная сингония, пр. группа $C 2 / m$ ) обнаружено [28] варьирование кристаллической структуры по образцу, даже в пределах одного нитевидного кристалла. Имеет место чередование упорядоченных и разупорядоченных участков. Такое поведение типично для т.н. несоразмерных фаз, и аналогично поведению муллита [32].

\section{СИНТЕЗ ПОРОШКОВ БОРАТОВ АЛЮМИНИЯ}

Предложено много способов синтеза порошков боратов алюминия.

Прямое спекание $\mathrm{Al}_{2} \mathrm{O}_{3}$ и $\mathrm{B}_{2} \mathrm{O}_{3}$ при $800-1100{ }^{\circ} \mathrm{C}$ позволяет получать последовательно фазы $2 \mathrm{Al}_{2} \mathrm{O}_{3} \cdot \mathrm{B}_{2} \mathrm{O}_{3}$

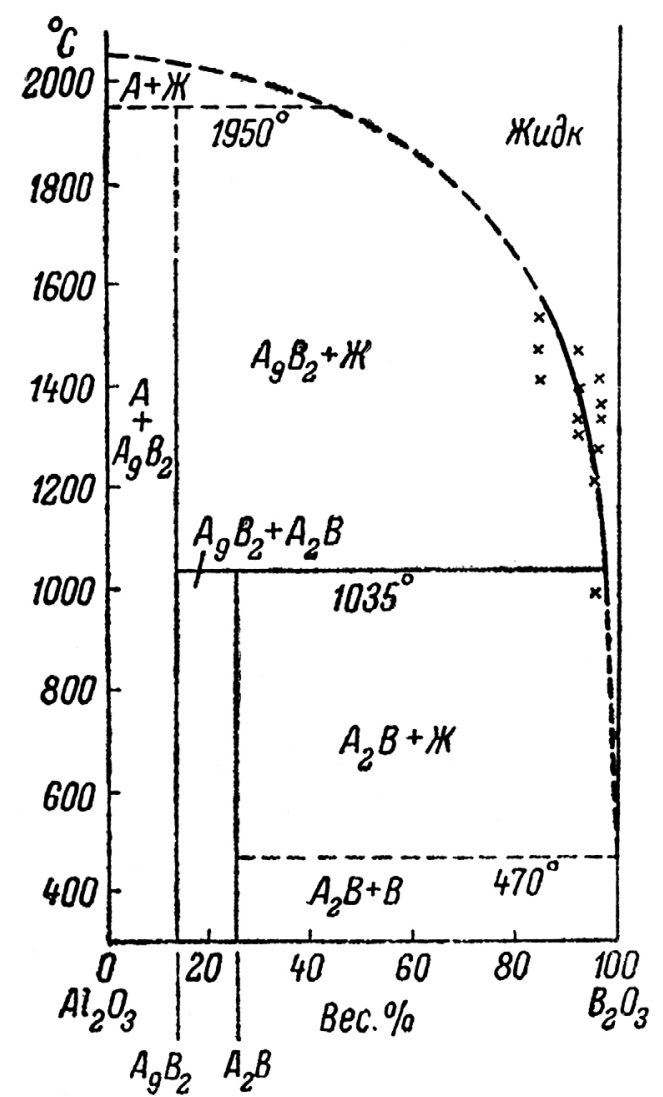

Рис. 1. Диаграмма состояния системы $\mathrm{Al}_{2} \mathrm{O}_{3}-\mathrm{B}_{2} \mathrm{O}_{3}$ по данным [1]

[Fig. 1. Phase diagram of the system $\left.\mathrm{Al}_{2} \mathrm{O}_{3}-\mathrm{B}_{2} \mathrm{O}_{3}[1]\right]$

и $9 \mathrm{Al}_{2} \mathrm{O}_{3} \cdot \mathrm{B}_{2} \mathrm{O}_{3}$, но не дает нитевидных кристаллов [6]. Спек поликристаллического бората алюминия состава $9 \mathrm{Al}_{2} \mathrm{O}_{3} \cdot 2 \mathrm{~B}_{2} \mathrm{O}_{3}$, представляющий собой микрокристаллы изометричной формы, синтезировали А. Камарзин и др. из шихты состава $\mathrm{AlN}_{3}+\mathrm{H}_{3} \mathrm{BO}_{3}$ в мольном соотношении 9:2 путем прокаливания в кварцевой ампуле при $1100{ }^{\circ} \mathrm{C}$ в течение 1 ч. [13].

Золь-гель процесс использован для синтеза как боратов алюминия, так и смешанных фаз со структурой муллита в системе $\mathrm{Al}_{2} \mathrm{O}_{3}-\mathrm{B}_{2} \mathrm{O}_{3}-\mathrm{SiO}_{2}$ [18]. Порошки боратов алюминия различной морфологии получены методом нитратного горения [28]. Нитрат алюминия $\mathrm{Al}\left(\mathrm{NO}_{3}\right)_{3} \cdot 9 \mathrm{H}_{2} \mathrm{O}$ и борная кислота растворялись в глицерине, нагревались и выдерживались 5 часов при $1200^{\circ} \mathrm{C}$.

Нитевидные кристаллы бората алюминия, представляющие промышленный интерес, по данным многих авторов были синтезированы в широком диапазоне составов от $2 \mathrm{Al}_{2} \mathrm{O}_{3} \cdot \mathrm{B}_{2} \mathrm{O}_{3}$ до $9 \mathrm{Al}_{2} \mathrm{O}_{3} \cdot \mathrm{B}_{2} \mathrm{O}_{3}$ в присутствии жидкой фазы.

Китамура и др. [2] запатентовали общий способ получения нитевидных кристаллов боратов алюминия состава $9 \mathrm{Al}_{2} \mathrm{O}_{3} \cdot 2 \mathrm{~B}_{2} \mathrm{O}_{3}$ или $2 \mathrm{Al}_{2} \mathrm{O}_{3} \cdot \mathrm{B}_{2} \mathrm{O}_{3}$ путем нагрева алюминий- и борсодержащих соединений в 
присутствии хлоридов, сульфатов и карбонатов щелочных металлов, используемых в качестве флюса. При нагревании алюмосодержащий компонент превращается в активный оксид алюминия. При температуре $900-1400{ }^{\circ} \mathrm{C}$ в промежутке от 0.5 до 8 часов образуются нитевидные кристаллы, после чего они подвергаются обработке горячими растворами кислот для растворения флюса и остатков непрореагировавшей шихты. Нитевидные кристаллы отделяют декантацией, отстаиванием и кипячением. В частности, нитевидные кристаллы состава $2.76 \mathrm{Al}_{2} \mathrm{O}_{3} \cdot \mathrm{B}_{2} \mathrm{O}_{3}$ синтезированы при обжиге шихты (вес. \%): $20 \mathrm{Al}(\mathrm{OH})_{3}$ и $80 \mathrm{~B}_{2} \mathrm{O}_{3}$ в платиновом тигле при $1400{ }^{\circ} \mathrm{C}$ в течение 30 минут. Выход кристаллов составил $8 \%$ [2]. Их диаметр равнялся 10 мкм, длина $100-500$ мкм. Борат алюминия состава $4.87 \mathrm{Al}_{2} \mathrm{O}_{3} \cdot \mathrm{B}_{2} \mathrm{O}_{3}$ был получен путем обжига шихты (вес. \%): $40 \mathrm{Al}_{2} \mathrm{O}_{3} ; 50 \mathrm{Na}_{2} \mathrm{~B}_{4} \mathrm{O}_{7}$; $10 \mathrm{~B}_{2} \mathrm{O}_{3}$ при температуре $1400{ }^{\circ} \mathrm{C}$ в течение 1 часа. Выход кристаллов толщиной около 10 мкм и длиной 200-3000 мкм составил 5 \% [2].

Гёненли и др. [12] синтезировали нитевидные кристаллы $9 \mathrm{Al}_{2} \mathrm{O}_{3} \cdot 2 \mathrm{~B}_{2} \mathrm{O}_{3}$ при $1150{ }^{\circ} \mathrm{C}$ из раствора в расплаве $\mathrm{K}_{2} \mathrm{SO}_{4}$, в качестве исходных веществ используя $\mathrm{Al}_{2}\left(\mathrm{SO}_{4}\right)_{3} \cdot 18 \mathrm{H}_{2} \mathrm{O}$ и борную кислоту. Этот флюс был выбран в качестве оптимального также в работе [14] при использовании тех же исходных веществ. Простые методы синтеза нитевидных кристаллов $9 \mathrm{Al}_{2} \mathrm{O}_{3} \cdot 2 \mathrm{~B}_{2} \mathrm{O}_{3}$ из раствора в расплаве $\mathrm{K}_{2} \mathrm{SO}_{4}$ («molten salt synthesis method») предложены в работах $[23,24]$. В качестве исходных реагентов использованы борная кислота, а также $\mathrm{KAl}\left(\mathrm{SO}_{4}\right) \cdot 12 \mathrm{H}_{2} \mathrm{O}$ [23] или $\mathrm{NH}_{4} \mathrm{Al}(\mathrm{OH})_{2} \mathrm{CO}_{3}$ [24]. В последнем случае процесс проводят при $1100{ }^{\circ} \mathrm{C}$, и уравнения реакций могут быть записаны следующим образом:

$$
\begin{gathered}
4 \mathrm{H}_{3} \mathrm{BO}_{3} \rightarrow 2 \mathrm{~B}_{2} \mathrm{O}_{3}(\mathrm{~s})+6 \mathrm{H}_{2} \mathrm{O}(\mathrm{g}), \\
2 \mathrm{~B}_{2} \mathrm{O}_{3}(\mathrm{~s}) \rightarrow 2 \mathrm{~B}_{2} \mathrm{O}_{3}(\mathrm{l}), \\
18 \mathrm{NH}_{4} \mathrm{Al}(\mathrm{OH})_{2} \mathrm{CO}_{3}(\mathrm{~s}) \rightarrow \\
\rightarrow 9 \mathrm{Al}_{2} \mathrm{O}_{3}(\mathrm{~s})+27 \mathrm{H}_{2} \mathrm{O}(\mathrm{g})+18 \mathrm{CO}_{2}(\mathrm{~g})+18 \mathrm{NH}_{3}(\mathrm{~g}), \\
9 \mathrm{Al}_{2} \mathrm{O}_{3}(\mathrm{~s})+2 \mathrm{~B}_{2} \mathrm{O}_{3}(\mathrm{l}) \rightarrow \mathrm{Al}_{18} \mathrm{~B}_{4} \mathrm{O}_{33}(\mathrm{~s}) .
\end{gathered}
$$

Реади [7] получил нитевидные кристаллы $9 \mathrm{Al}_{2} \mathrm{O}_{3} \cdot 2 \mathrm{~B}_{2} \mathrm{O}_{3}$ путем термического разложения прекурсора $\mathrm{Al}(\mathrm{OH})_{2}\left(\mathrm{OOCCH}_{3}\right) 1 / 3 \mathrm{HBO}_{3}$ при $1000^{\circ} \mathrm{C}$. Использование добавок поливинилпиралидона (PVP) в эту систему позволило получать нитевидные кристаллы с узким разбросом по диаметру, который можно регулировать, варьируя концентрацию PVP [26].

Предложена технология синтеза бората алюминия состава $9 \mathrm{Al}_{2} \mathrm{O}_{3} \cdot 2 \mathrm{~B}_{2} \mathrm{O}_{3}$ в виде игольчатых кристаллов из тройной системы $\mathrm{AlF}_{3}-\mathrm{SiO}_{2}-\mathrm{B}_{2} \mathrm{O}_{3}$ [3]. Кристаллизация происходит в результате минерализующего действия газообразного $\mathrm{SiF}_{4}$, который образовывается в результате реакции $\mathrm{AlF}_{3}+\mathrm{SiO}_{2} \rightarrow$ $\mathrm{Al}_{2} \mathrm{O}_{3}+\mathrm{SiF}_{4}$. Появление активного оксида алюминия позволяет снизить температуру синтеза до $1050-1150{ }^{\circ} \mathrm{C}$. Полученные вискерсы представляют собой длиннопризматические кристаллы толщиной 0.5-10 мкм и длиной 5-100 мкм. Насыпная масса порошка равна 0.30 г/см³. Интересным свойством нитевидного бората алюминия является сильная электризация иголочек при трении.

Синтезированы также микротрубки $9 \mathrm{Al}_{2} \mathrm{O}_{3} \cdot 2 \mathrm{~B}_{2} \mathrm{O}_{3}$ (ширина 1-15 мкм, длина до сотен мкм) прямой реакцией $\mathrm{Al}_{2} \mathrm{O}_{3}$ и $\mathrm{BN}$ на воздухе при $1700^{\circ} \mathrm{C}, 4$ ч. [15].

Свойства $9 \mathrm{Al}_{2} \mathrm{O}_{3} \cdot 2 \mathrm{~B}_{2} \mathrm{O}_{3}$ суммированы в табл. 1 . Соединение обладает низкой плотностью и низким коэффициентом термического расширения.

\begin{tabular}{|c|c|c|}
\hline $\begin{array}{l}\text { Характеристика } \\
\text { [Characteristic] }\end{array}$ & $\begin{array}{l}\text { Размер- } \\
\text { ность } \\
\text { [Dimen- } \\
\text { sion] }\end{array}$ & $\begin{array}{c}\text { Величина } \\
\text { [Value] }\end{array}$ \\
\hline $\begin{array}{c}\text { Плотность } \\
\text { [Density] }\end{array}$ & $\begin{array}{c}\Gamma / \mathrm{cm}^{3} \\
{\left[\mathrm{~g} / \mathrm{cm}^{3}\right]} \\
\end{array}$ & 2.96 \\
\hline $\begin{array}{c}\text { Теплопроводность } \\
\text { [Thermal conductivity] }\end{array}$ & $\begin{array}{c}\mathrm{BT} / \mathrm{M} \cdot \mathrm{K} \\
{[\mathrm{W} / \mathrm{m} \cdot \mathrm{K}]}\end{array}$ & $4-6$ \\
\hline $\begin{array}{c}\text { Модуль Юнга } \\
\text { [Young's modulus] }\end{array}$ & $\begin{array}{c}\text { ГПа } \\
{[\mathrm{GPa}]}\end{array}$ & 400 \\
\hline $\begin{array}{l}\text { Твердость по Моocy } \\
\text { [Mohs hardness] }\end{array}$ & & 7 \\
\hline \begin{tabular}{|c} 
Коэффициент термического \\
расширения: \\
- аксиальный \\
- радиальный \\
[Coefficient of thermal expansion: \\
- axial \\
- radial]
\end{tabular} & $10^{-6} \mathrm{~K}^{-1}$ & $\begin{array}{l}\sim 4.5 \\
\sim 1.9\end{array}$ \\
\hline
\end{tabular}

Таблица 1. Физические свойства бората алюминия $9 \mathrm{Al}_{2} \mathrm{O}_{3} \cdot 2 \mathrm{~B}_{2} \mathrm{O}_{3}[30]$

[Table 1. Physical properties of aluminum borate $\left.9 \mathrm{Al}_{2} \mathrm{O}_{3} \cdot 2 \mathrm{~B}_{2} \mathrm{O}_{3}[30]\right]$

\section{ПОЛУЧЕНИЕ КЕРАМИКИ}

Керамика на основе бората алюминия $\left(9 \mathrm{Al}_{2} \mathrm{O}_{3} \cdot 2 \mathrm{~B}_{2} \mathrm{O}_{3}\right)$ представляет особый промышленный интерес благодаря схожести своих свойств с муллитом. Материал обладает высоким модулем упругости, пределом прочности на разрыв, высокой окислительной и коррозионной стойкостью.

Плотная керамика $9 \mathrm{Al}_{2} \mathrm{O}_{3} \cdot 2 \mathrm{~B}_{2} \mathrm{O}_{3}$ (плотность 96-98 \% от теоретической) получена как методикой горячего прессования при $1350{ }^{\circ} \mathrm{C}$ и давлении 34.5 МПа, так и спеканием на воздухе при 1250 $1400{ }^{\circ} \mathrm{C}$ с использованием спекающих добавок $\left(\mathrm{CaO}, \mathrm{CaAl}_{2} \mathrm{~B}_{2} \mathrm{O}_{7}, \mathrm{MgO}\right)[6]$. 
Пористая керамика представляет интерес для таких технологических операций, как фильтрация, адсорбция, катализ и поддержка катализатора. Пористая керамика с каркасом из нитевидных кристаллов $9 \mathrm{Al}_{2} \mathrm{O}_{3} \cdot 2 \mathrm{~B}_{2} \mathrm{O}_{3}$ синтезирована в работах $[11,29,30]$. Проводилось спекание исходного компакта из гидроксида [11] или оксида алюминия [30] и борной кислоты на воздухе при $1200-1300{ }^{\circ} \mathrm{C}$ [30]. Добавка оксида никеля [11] позволила снизить температуру синтеза до $1100{ }^{\circ} \mathrm{C}$. Пористость составила 85-50 \%.

На настоящий момент процессы синтеза бората алюминия из природных веществ и влияние спекающих добавок на формирование структуры и свойств керамики на его основе слабо изучены. Однако для промышленного применения снижение себестоимости производства данного материала представляется существенным.

Синтез бората алюминия из исходных оксидов, так же как и синтез игольчатого силиката алюминия (муллита), протекает с увеличением объема, что является определенной технологической трудностью при получении прочной керамики из подобных материалов, если совмещать в одну стадию синтез материала и спекание изделия. Поэтому в работе [20] был осуществлен синтез бората алюминия из природных веществ и получена керамика на их основе, а также изучено влияние добавки $\mathrm{CaO}$ на синтез и структуру материала. Введение $\mathrm{CaO}$ в состав исходной сырьевой смеси способствует формированию игольчатых кристаллов и увеличению выхода фазы бората алюминия, а также снижению плотности материала, а двухстадийный обжиг позволяет повысить прочность образцов с добавкой $\mathrm{CaO}$ с сохранением низкой плотности.

Авторами [4] была получена легковесная керамика на основе бората алюминия путем процесса синтеза и спекания одновременно в одну стадию в системе $\mathrm{Al}_{2} \mathrm{O}_{3}-\mathrm{B}_{2} \mathrm{O}_{3}-\mathrm{AlF}_{3}$. Шихту обжигают при $1000-1400{ }^{\circ} \mathrm{C}$ и давлении 0.1-0.3 МПа в течение 0.5-20 часов. Процесс дает более высокий выход конечного продукта (88-92 \% к массе исходной шихты). Примеси представлены корундом и стеклофазой в незначительном количестве (1-3\%). Керамический материал может изготавливаться в виде конструкционных блоков с последующей механической обработкой для придания нужной формы и размеров. Низкая теплопроводность керамики и высокая пористость в сочетании с огнеупорностью позволяет использовать ее при изготовлении высокотемпературной изоляции. Высокое содержание бора (13\%) характеризует продукт как эффективный поглотитель нейтронного излучения.

\section{КОМПОЗИЦИОННЫЕ МАТЕРИАЛЫ}

Внимание к композиционным материалам в последнее время непрерывно возрастает. Это объясняется тем, что возможности повышения механических свойств традиционных конструкционных материалов в значительной степени исчерпаны.

Композиционные материалы по удельным прочности и жесткости, прочности при высокой температуре, сопротивлению усталостному разрушению и другим свойствам значительно превосходят все известные конструкционные сплавы.

Свойства композиционных материалов в основном зависят от физико-механических свойств ком-

Таблица 2. Свойства керамического бората алюминия [13]

[Table 2. Properties of ceramic borate aluminum [13]]

\begin{tabular}{|c|c|c|}
\hline \multirow{2}{*}{$\begin{array}{c}\text { Характеристика } \\
\text { [Characteristic] }\end{array}$} & \multicolumn{2}{|c|}{$\begin{array}{l}\text { Показатель } \\
\text { [Index] }\end{array}$} \\
\hline & $\begin{array}{l}\text { Плотная керамика } \\
\text { [Dense ceramics] }\end{array}$ & $\begin{array}{c}\text { Легковес } \\
\text { [Lightweight] }\end{array}$ \\
\hline $\begin{array}{c}\text { Цвет } \\
{[\text { Colour }]}\end{array}$ & $\begin{array}{c}\text { Белый } \\
\text { [White] }\end{array}$ & $\begin{array}{c}\text { Белый } \\
\text { [White] }\end{array}$ \\
\hline $\begin{array}{l}\text { Форма } \\
\text { [Form] }\end{array}$ & $\begin{array}{c}\text { По форме тигля } \\
\text { [According to the shape of the crucible] }\end{array}$ & $\begin{array}{c}\text { По форме тигля } \\
\text { [According to the shape of the crucible] }\end{array}$ \\
\hline 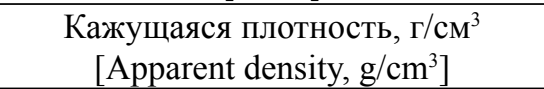 & 2.92 & $0.8-0.85$ \\
\hline $\begin{array}{c}\text { Открытая пористость, \% } \\
\text { [Open porosity,\%] }\end{array}$ & 1 & $52-61$ \\
\hline $\begin{array}{c}\text { Предел прочности при сжатии, Мпа } \\
\text { [Compressive strength, MPa] }\end{array}$ & - & $17.6-21.4$ \\
\hline $\begin{array}{c}\text { Теплопроводность, Вт/(м·K) } \\
\text { [Thermal conductivity, } \mathrm{W} /(\mathrm{m} \cdot \mathrm{K})]\end{array}$ & 6.5 & $0.42-0.47$ \\
\hline $\begin{array}{l}\text { Твердость по Виккерсу } \\
\text { [Vickers hardness] }\end{array}$ & 1300 & - \\
\hline
\end{tabular}


понентов и прочности связи между ними. Отличительной особенностью данных материалов является то, что в них проявляются достоинства компонентов, а не их недостатки. Вместе с тем композиционным материалам присущи свойства, которыми не обладают отдельно взятые компоненты, входящие в их состав. Для оптимизации свойств композиции выбирают компоненты с резко отличающимися, но дополняющими друг друга свойствами.

По своему составу композиционные материалы состоят из основы (матрицы) и наполнителя (упрочнителя, армирующего компонента). Основой (матрицей) композиционных материалов служат металлы или сплавы, полимеры, углеродные и керамические материалы. Матрица связывает композицию, придает ей форму.

Нитевидные кристаллы алюмоборатов являются прекрасными наполнителями в металл-керамических композитах. Добавки нитевидных кристаллов $9 \mathrm{Al}_{2} \mathrm{O}_{3} \cdot 2 \mathrm{~B}_{2} \mathrm{O}_{3}$ используются для упрочнения сплавов различного состава, в первую очередь алюминиевых, $[9,10,22,27]$. Использовались такие сплавы, как (вес. \%): 2024Al (Cu 4.79, Mg 1.49, Mn 0.611, Fe 0.245, Al остальное) [22]; 60601Al (Cu 0.34, Mg 0.75, Si 1.26, $\mathrm{Ti}<0.15, \mathrm{Ni}<0.15, \mathrm{Zn}<0.15$, Al остальное) [27]. Преимуществами являются превосходные механические характеристики композита, в том числе при повышенных температурах, и низкая цена в сравнении с вискерсами из карбида кремния. Алюмоборатные вискерсы обозначаются в литературе как $\mathrm{ABOw}$.

В работе [9] исследовано влияние температуры разливки на модуль Юнга упрочненного сплава, содержащего 25 об.\% вискерсов. Состав спла- ва (вес. \%): Si 12.0, Mg 1.0, Cu 0.8, Ni 1.0, Al 85.2. Решающую роль в разрушении композита играет фаза $\mathrm{MgAl}_{2} \mathrm{O}_{4}$, образующаяся на поверхности раздела металл/ABOw. Для улучшения механических свойств композита предложено покрывать поверхность $\mathrm{ABOw}$ тонким слоем $\mathrm{CuO}$ [27].

Для тонкой фильтрации автомобильных выхлопов был создан композит $\mathrm{SiC} / \mathrm{Al}_{4} \mathrm{~B}_{2} \mathrm{O}_{9}$, состоящий из пористой керамики из карбида кремния, в порах которой были осаждены вискерсы бората алюминия [25]. Среди композитных материалов с использованием алюмоборатов следует упомянуть также стеклокерамику [29].

\section{ЗАКЛЮЧЕНИЕ}

Таким образом, борат алюминия представляет значительный интерес как с чисто научной, так и с прикладной точек зрения. Борат алюминия - ярко выраженный полифункциональный материал.

Интерес представляют методы его получения; разнообразие химических реакций, используемых для проведении процессов синтеза, в том числе отбор оптимальных решений для реализации процессов в полупромышленных масштабах; реакции с участием твердых, жидких и газообразных фаз; управление процессами получения частиц заданной формы; механизмы роста нитевидных кристаллов.

С фундаментальной точки зрения интересны механизмы реализации нестехиометрии в кристаллах диэлектриков с жесткими ковалентными связями, фазовые равновесия, возможность образования несоразмерных фаз, сочетание порядка с элементами беспорядка в кристаллах.

\title{
ALUMINUM BORATE AND METHODS OF ITS SYNTHESIS OVERVIEW
}

\author{
(C) 2018 E. G. Yarotskaya, P. P. Fedorov \\ A. M. Prokhorov General Physics Institute RAS, 38 Vavilov str, 119991 Moscow, Russia \\ e-mail: yar461@yandex.ru
}

Received 05.06.2018

\begin{abstract}
An overview of various technologies for the synthesis of aluminum borate and a diagram of the state of the $\mathrm{Al2O} 3-\mathrm{B} 2 \mathrm{O} 3$ system are presented. The synthesis parameters and compositions of the initial components are presented. The habit of its crystals depends on the methods of preparation. The unique properties of aluminum borate are considered depending on the purpose of obtaining the final product. Properties of the obtained aluminum borate are given, its structure is studied using a wide range of research methods. Analysis of its properties made it possible to determine possible applications of materials based on porous ceramics in various industries.
\end{abstract}

Keywords: aluminum borate, whiskers, porous ceramics, composite materials

DOI: https://doi.org/10.17308/kcmf.2018.20/571 


\section{REFERENCES}

1. Giolisse P. J. M., Foster M. R. Nature, 1962, vol. 195, no. 4836 , p. 69 . DOI: $10.1038 / 195069 \mathrm{a} 0$

2. Kitamura T., Sakane K., Waola H., et. al. Process for Preparing Aluminium Borate Whiskers. US Pat. No. 4,925,641, May 15, 1990. Int.Cl ${ }^{5}$. CO1B 35/12.

3. Yarotskaya E. G., et. al. SU Pat. No. 1706160, March 29, 1990.

4. Yarotskaya E. G., et. al. SU Pat. No. 1799002, November 30, 1991.

5. Mazza D., Vallino M., Basco G. J. Amer. Ceram. Soc., 1992, vol. 75, pp. 1929-1934. DOI: 10.1111/j.11512916.1992.tb07219.x

6. Ray S. P. J. Amer. Ceram. Soc., 1992, vol. 75, no. 9, pp. 2605-2609. DOI: 10.1111/j.1151-2916.1992.tb05622.x

7. Readey M. J. J. Amer. Ceram. Soc., 1992, vol. 75, pp. 3452-3456. DOI: 10.1111/j.1151-2916.1992.tb04448.x

8. Wada H., Sakane K., Kitamura T. J. Mat. Sci. Let., 1993, vol. 12, pp. 1735-1737. DOI: 10.1007/bf00517595

9. Fei W. D., Jiang X. D., Li C., Yao C. K. J. Mat. Sci. Let., 1996, vol. 15, pp. 1966-1968. DOI: 10.1007/ bf00274351

10. Hu J., Xing Q. F., Yao C. K. J. Mat. Sci. Let., 1997, vol. 16, pp. 835-836. DOI: 10.1023/a:1018590711207

11. Li J. X., Narita T., Ogawa J., Wadasako M. J. Mat. Sci., 1998, vol. 33, pp. 2601-2605. DOI: 10.1023/ a:1004309403901

12. Gönenli I. E., Tas A. C. Powder diffraction, 2000, vol. 15(2), pp. 104-107. DOI: 10.1017/ s0885715600010927

13. Golenko V. P., Polyanskii E. V., Yarotskaya E. G., Yarotskii V. G. in "Synthesis of Minerals". Alexandrov, VNIISIMS Publ., 2000, vol. 2, pp. 179-182. (in Russ.)

14. Carazeanu I., Ciupina V., Guguta C., Prodan G. Microchim. Acta, 2004, vol. 147, pp. 147-150. DOI: 10.1007/s00604-004-0185-7

15. Yang W., Xie Zh., Ma J., et al. J. Amer. Ceram. Soc., 2005, vol. 88, pp. 485-487. DOI: $10.1111 / \mathrm{j} .1551-$ 2916.2005.00084.X

16. Mizuno K., Takahashi W., Beppu T., et. al. Plant Cell, Tissue and Organ Culture, 2005, vol. 80, pp. 163-169. DOI: $10.1007 /$ s11240-004-9542-9

17. MacKenzie K. J. D., Smith M. E., Kemp T. F., Voll D. Appl. Magn. Reson. 2007, vol. 32, pp. 647-662. DOI: $10.1007 / \mathrm{s} 00723-007-0044-\mathrm{x}$
18. Griesser K. J., Beran A., Voll D., Schneider H. Mineralogy and Petrology, 2008, vol. 92, pp. 309-320. DOI: 10.1007/s00710-007-0210-8

19. Fisch M., Armbruster T., Rentsch D., et. al. J. Solid State Chem., 2011, vol. 184, pp. 70-80. DOI: 10.1016/j. jssc.2010.10.032

20. Usova Z.Yu., Pogrebenkov V. M. Izv. Tomskogo Polytekh. Univers., 2011, vol. 319(3), p. 40. (in Russ.)

21. Shirokov A.V. Photoluminescent Properties of Oxide Luminescent Substances in the System $\left[\mathrm{Al}_{2} \mathrm{O}_{3} \times \mathrm{B}_{2} \mathrm{O}_{3} \times \mathrm{SiO}_{2}\right]: \mathrm{Eu}$. Cand. Diss. (Phys.-Math.), Ul'yanovsk, 2012. (in Russ.)

22. Yang Ch., Zong Y., Zheng Zh., Shan D. Mater. Charact., 2014, vol. 96, pp. 84-92. DOI: 10.1016/j. matchar.2014.07.024

23. Su P., Huang J., Wu W., Wu X. Ceram. Inter., 2013, vol. 39, pp. 7263-7267. DOI: 10.1016/j.ceramint.2013.02.007

24. Huang Y., Xia Y., Long Q., et. al. Ceram. Inter., 2015, vol. 41, pp. 2607-2610. DOI: 10.1016/j.ceramint.2014.10.012

25. Wang W., Wang B., Zhu H., et. al. J. Adv. Ceram., 2015, vol. 4, pp. 232-236. DOI: 10.1007/s40145-015-0154-0

26. Song X., Liu W., Wang J., et. al. Ceram. Inter., 2017, vol. 43, pp. 9831-9837. DOI: 10.1016/j.ceramint.2017.04.163

27. Yue H. Y., Wang B., Gao X. et. al. J. Alloys Compd., 2017, vol. 692, pp. 395-402. DOI: 10.1016/j.jallcom.2016.09.082

28. Hoffman K., Hooper T. J. N., Zhao H. J. Solid State Chem., 2017, vol. 247, pp. 173-187. DOI: 10.1016/j. jssc.2016.12.027

29. Hernandez M.F., Suarez G., Cipollone M., et. al. Ceram. Inter., 2017, vol. 43, pp. 2188-2195. DOI: 10.1016/ j.ceramint.2016.11.002

30. Hernandez M. F., Suarez G., Cipollone M., et. al. Ceram. Inter., 2017, vol. 43, pp. 11759-11765. DOI: 10.1016/j.ceramint.2017.06.011

31. Givargizov E. I. Highly Anisotropic Crystals. Dortrecht e.a.: D. Reidel Publ. Comp., Tokyo: Terra Sci. Publ. Comp., 1987, 453p.

32. Padlewski S., Heine V., Price G. D. J. Phys.: Condens. Matter, 1993, vol. 5, pp. 3417-3430. DOI: 10.1088/0953-8984/5/21/004
Яроикая Евгения Григорьевна - к. х. н., н. с., Институт общей физики им. А. М. Прохорова РАН, тел.: +7 (499) 1357744, e-mail: yar461@yandex.ru

Федоров Павел Павлович - д. х. н., профессор, заведующий лабораторией, Институт общей физики им. А. М. Прохорова РАН, тел.: +7 (499) 5038292 , e-mail: ppfedorov@yandex.ru
Evgeniya G. Yarotskaya - Cand. Sci. (Chem.) Researcher, Prokhorov General Physics Institute, RAS; tel.: +7 (499) 1357744, e-mail: yar461@yandex.ru

Pavel P. Fedorov - Dr. Sci. (Chem.), Full Professor, Laboratory Head, Prokhorov General Physics Institute, RAS; tel.: +7 (499) 5038292, e-mail:ppfedorov@ yandex.ru 